\title{
Coffee Consumption and the Risk of Obesity in Korean Women
}

\author{
Jeonghee Lee ${ }^{1,+}$, Hye Young Kim ${ }^{1,2,+}$ and Jeongseon Kim ${ }^{1, *}$ \\ 1 Department of Cancer Biomedical Science, Graduate School of Cancer Science and Policy, \\ National Cancer Center, Goyang-si 10408, Korea; jeonghee@ncc.re.kr (J.L.); hypkim@yongin.ac.kr (H.Y.K.) \\ 2 Department of Foods and Nutrition, Yongin University, Yongin 17092, Korea \\ * Correspondence: jskim@ncc.re.kr; Tel.: +82-31-920-2579 \\ + These authors contributed equally to this work.
}

Received: 29 September 2017; Accepted: 6 December 2017; Published: 8 December 2017

\begin{abstract}
Instant coffee mixes that contain sugar and non-dairy creamer account for $80-90 \%$ of the total coffee market in Korea. The objective of this study was to investigate the relationship between coffee consumption and obesity in Korean women. We included 5995 women who participated in a health screening examination at the Korean National Cancer Center between 2007 and 2016. Daily coffee consumption and the use of sugar and creamer in coffee was evaluated using a 106-item food frequency questionnaire. Obesity was assessed by body mass index (BMI), and abdominal obesity was assessed by waist circumference (WC). A multiple logistic regression model was used to calculate the odds ratio (OR) of obesity according to coffee consumption. After multivariate adjustment, high coffee consumption was positively associated with obesity as measured by BMI ( $\geq 3$ cups vs. no drinks, $\mathrm{OR}=2.52 ; 95 \%$ confidence interval $(\mathrm{CI})=1.91-3.34 ; p$ for the trend $<0.001)$ and abdominal obesity as measured by WC ( $\geq 3$ cups vs. no drinks, $\mathrm{OR}=2.11 ; 95 \% \mathrm{CI}=1.59-2.79 ; p$ for the trend $<0.001$ ). The positive association between daily coffee consumption and obesity prevalence was not altered by menopause. The amount of coffee with additives consumed per day by Korean women was positively correlated with the prevalence of obesity, but causation cannot be determined due to the cross-sectional nature of the study design. The mechanism underlying the observed relationship is yet to be elucidated.
\end{abstract}

Keywords: coffee; obesity; body mass index; waist circumference

\section{Introduction}

Obesity is a major global public health problem. The World Health Organization (WHO) describes obesity as a global epidemic due to the rapid increase in the number of obese people [1]. In 2014, approximately $53 \%$ of adults in the world were overweight or obese [2]. Risks of hypertension, cardiovascular disease, type 2 diabetes mellitus and some types of cancer steadily increase with increasing body mass index (BMI) [3-5]. Mortality rates also increase with higher degrees of overweight [6]. Obesity is influenced by many dietary factors, including an increase in beverage consumption [6,7]. Increased sugar-sweetened beverage or fruit juice intake has been found to be associated with increased weight gain in women $[7,8]$.

Coffee is one of the most popular beverages in the world. As eating habits have become westernized and lifestyles have changed, the culture of drinking coffee has become common in Korea [9]. Steady increases in the quantity of coffee imports and the consumption of coffee have been reported [10]. The average frequency of coffee consumption by Korean adults have increased from 9 times per week in 2008 to 12 times per week in 2015 [11].

The influence of coffee on human health and disease has long been a topic of interest $[12,13]$. Coffee contains several bioactive chemicals, such as caffeine, chlorogenic acid, and diterpenes, which 
have various effects on the human body [14]. Caffeine increases heat production and lipid peroxidation to increase weight loss, chlorogenic acid positively affects glucose metabolism, and diterpenes exert anti-inflammatory effects $[15,16]$.

For many years, epidemiological studies investigating the association between coffee drinking and obesity based on BMI and waist circumference (WC) yielded inconsistent results. Coffee consumption was reported to be effective in preventing obesity by decreasing body weight and BMI in some studies [17-21], but other studies reported an increase in BMI and WC as coffee consumption increased [22,23]. Several other studies did not observe an association between coffee intake and obesity risk [24-27].

Because styles of drinking coffee vary by country and culture [12,28], research results from other countries are not directly applicable to people in Korea. Traditionally, Koreans favor drinking coffee with sugar and creamer added. Instant coffee mixes that contain sugar and non-dairy creamer account for $80-90 \%$ of the total coffee market in Korea [10]. Few studies have investigated the relationship between consumption of coffee with additives and obesity. Therefore, in this study, we aimed to evaluate the BMI and WC of Korean women based on their daily consumption of coffee with additives and to investigate the relationship between the consumption of coffee with additives and obesity risk. A subgroup analysis stratified by menopausal status was also performed to examine the possibility that menopause serves as a moderating variable.

\section{Materials and Methods}

\subsection{Study Population}

A total of 9669 female participants were recruited from a health screening examination at the National Cancer Center (NCC) in South Korea between October 2007 and December 2016. Three thousand three hundred nine participants who failed to complete the general questionnaire and food frequency questionnaire (FFQ) as well as participants with daily energy intakes of $<500 \mathrm{kcal}$ or $>5000$ $\mathrm{kcal}(n=60)$ were excluded from the analysis. Information about height, weight, and WC were missing for 305 participants, who were also excluded. As a result, 5995 female participants ranging in age from 30 to 70 years old were included in the final analysis (Figure 1). The study protocol was approved by the Institutional Review Board (IRB) of the NCC (IRB No. NCCNCS-07-077). All participants provided written informed consent and ethical approval for publication prior to participation. The study protocols were performed according to the guidelines and regulations of the IRB of the NCC.

\subsection{Data Collection}

Each participant was asked to complete a self-administered questionnaire about her sociodemographic characteristics (e.g., age, education, and occupation), cigarette smoking habits, alcohol consumption, regular exercise habits, menstrual history, and history of hormone therapy. Usual dietary intake was assessed with the validated 106-item FFQ [29] over the past year, which included coffee consumption and the use of sugar and creamers in coffee. All subjects were interviewed about their average frequencies of intake and portion sizes of specific foods during the previous year. Consumption frequencies were divided into 9 categories: seldom or never, once a month, 2-3 times a month, 1-2 times a week, 3-4 times a week, 5-6 times a week, once a day, twice a day and 3 times a day. Portion sizes were classified into 3 categories: small, medium, and large. The average coffee consumption was calculated according to the standard portion size used in the study and then converted to daily intake. Coffee, coffee sugar, and coffee cream intake were computed by multiplying the frequency of consumption of each item by portion size. For simplicity, average coffee consumption was divided into none, $<1$ cup a day, 1 to $<2$ cups a day, 2 to $<3$ cups a day, and $\geq 3$ cups a day. Daily nutrient intakes and total calorie intake were determined using CAN-Pro 4.0 (Computer Aided Nutritional Analysis Program, The Korean Nutrition Society, Seoul, Korea). 
Health screening center (2007.10-2016.12)

9669 women visitors for whom questionnaire, dietary, and clinical data were available

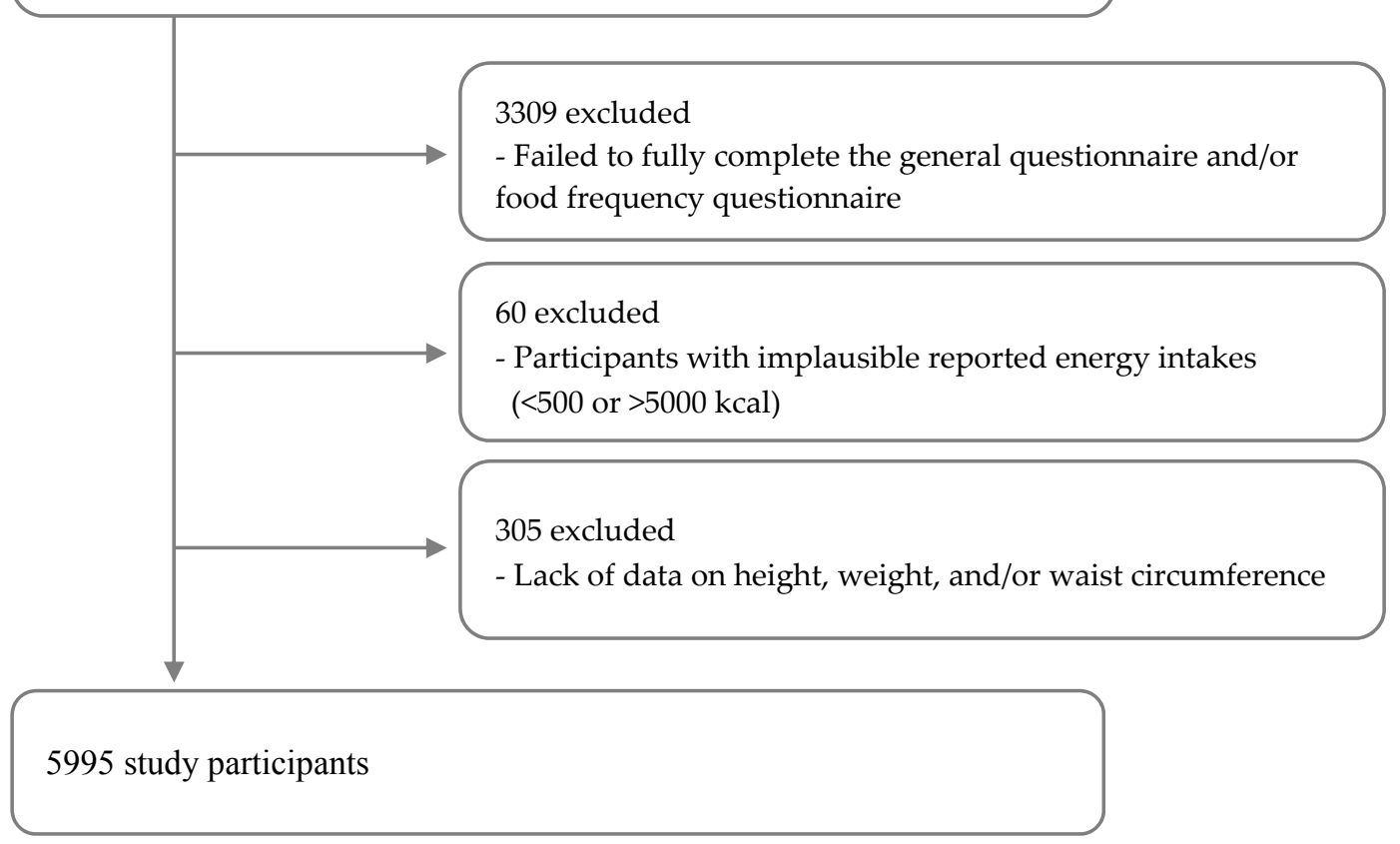

Figure 1. Flow chart of study selection process.

At the time of the screen, body weight was measured to the nearest $0.1 \mathrm{~kg}$ when subjects were wearing light clothes. Height was measured to the nearest $0.1 \mathrm{~cm}$ when subjects were standing without shoes. The height and weight of each subject were determined using the height \& weight scale DS-103 (Dong Sahn Jenix, Seoul, Korea). BMI was calculated as weight in kilograms divided by the square of height in meters $\left(\mathrm{kg} / \mathrm{m}^{2}\right)$. WC was measured to the nearest $0.1 \mathrm{~cm}$ using a measuring tape above the umbilicus at minimal respiration. In the present study, a BMI greater than $25 \mathrm{~kg} / \mathrm{m}^{2}$ and a waist circumference greater than $80 \mathrm{~cm}$ indicated obesity and abdominal obesity, respectively, according to the WHO Asian-Pacific guidelines [30].

\subsection{Statistical Analysis}

Categorical variables are presented as frequencies and percentages, and continuous variables are shown as the means and standard deviations (SDs). The $p$ value for trends was calculated using Mantel-Haenszel chi-square tests for the categorical variables and generalized linear models (GLM) for continuous variables. Differences in the means for BMI and WC among subgroups with different levels of coffee consumption were statistically tested with GLM. GLM was also used to estimate the adjusted means and proportions among subgroups with different levels of coffee consumption after adjusting for covariates. To assess the association between coffee consumption and the prevalence of obesity, multiple logistic regression models were used to calculate odds ratios (ORs) and 95\% confidence intervals (CIs). Model 1 was unadjusted. Model 2 was adjusted for age (continuous), education level (less than middle school, high school, or college or more), occupation (managers and professionals, office workers, laborers, or not in the labor force), alcohol consumption (non-drinker, ex-drinker, or current drinker), smoking status (non-smoker, ex-smoker, or current smoker), regular exercise (no or yes), and total calorie intake (continuous). Model 3 was adjusted for the covariates in Model 2 in addition to the use of sugar and creamer additives. We conducted subgroup analyses of coffee consumption and obesity risk stratified by menopausal status and implemented an additional 
adjustment for postmenopausal hormone use in the analysis of postmenopausal women. Linear trends across the coffee consumption categories were tested by assigning the median value of the category $(0,0.25,1,2$, or 3 cups/day) to each participant and modeling this value as a continuous variable. SAS 9.4 software (SAS Institute, Inc., Cary, NC, USA) was used to perform the calculations, and a 2-sided $p$ value less than 0.05 was considered statistically significant.

\section{Results}

The general characteristics of the study participants stratified by coffee consumption category are shown in Table 1. Participants with the highest coffee consumption ( 3 or more cups/day) tended to be younger (mean 49.7 years), have more education, have lower unemployment rates, be current drinkers, be current smokers and exercise less regularly. They also tended to have a higher total energy intake and used more coffee additives, such as sugar and creamer.

The anthropometric measurements of the study participants stratified by coffee consumption category are shown in Table 2. Significantly positive trends across coffee consumption frequency were observed for height, weight, BMI, and WC. The results were similar for Model 2, which was adjusted for age, education level, occupation, alcohol intake, smoking status, regular exercise and total energy intake. However, height did not significantly differ among the coffee consumption groups. Model 3 was further adjusted for the use of sugar and creamer additives, and significantly positive trends in weight, BMI, and WC with increasing frequency of coffee consumption were observed.

Table 3 presents the OR for the prevalence of obesity as defined by BMI $(\geq 25)$ in relation to coffee consumption. In the multivariate logistic regression model, high coffee consumption was positively associated with obesity ( $\geq 3$ cups vs. no drinks, $\mathrm{OR}=2.52 ; 95 \% \mathrm{CI}=1.91-3.34 ; p$ for the trend $<0.001$ ). After stratifying participants by menopausal status, a positive association between coffee consumption and BMI remained for both premenopausal $(\mathrm{OR}=2.28,95 \% \mathrm{CI}=1.36-3.82 ; p$ for the trend $=0.006)$ and postmenopausal $(\mathrm{OR}=2.52,95 \% \mathrm{CI}=1.79-3.54 ; p$ for the trend $<0.001)$ women.

Table 4 shows the OR for the prevalence of abdominal obesity as defined by WC in relation to coffee consumption. In the multivariate logistic regression model, high coffee consumption was positively associated with obesity ( $\geq 3$ cups vs. no drinks, $\mathrm{OR}=2.11 ; 95 \% \mathrm{CI}=1.59-2.79 ; p$ for the trend $<0.001)$. After stratifying participants by menopausal status, a positive association with abdominal obesity remained for both premenopausal $(\mathrm{OR}=2.82,95 \% \mathrm{CI}=1.55-5.12 ; p$ for the trend $=0.010)$ and postmenopausal $(\mathrm{OR}=1.90,95 \% \mathrm{CI}=1.36-2.67 ; p$ for the trend $=0.001)$ women. 
Table 1. General characteristics of the study participants stratified by coffee consumption category ${ }^{1}$.

\begin{tabular}{|c|c|c|c|c|c|c|}
\hline \multirow[b]{2}{*}{ Characteristics } & \multirow[b]{2}{*}{ None $(n=725)$} & \multicolumn{3}{|c|}{ Daily Coffee Consumption } & \multirow[b]{2}{*}{$\geq 3$ Cups/Day $(n=989)$} & \multirow[b]{2}{*}{$p$ for Trend ${ }^{2}$} \\
\hline & & $<1$ Cup/Day $(n=1646)$ & 1-2 Cups/Day $(n=1457)$ & 2-3 Cups/Day $(n=1178)$ & & \\
\hline Age (years) & $54.5 \pm 8.3$ & $53.4 \pm 8.3$ & $52.3 \pm 8.2$ & $50.2 \pm 7.6$ & $49.7 \pm 7.4$ & $<0.001$ \\
\hline \multicolumn{7}{|l|}{ Education level } \\
\hline Under middle school & $168(23.2)$ & $310(18.8)$ & $202(13.9)$ & $115(9.8)$ & $100(10.1)$ & $<0.001$ \\
\hline High school & $282(38.9)$ & $642(39.0)$ & $584(40.1)$ & $491(41.7)$ & $406(41.1)$ & \\
\hline College or more & $236(32.6)$ & $601(36.5)$ & $609(41.8)$ & $523(44.4)$ & $446(45.1)$ & \\
\hline Missing $^{3}$ & $39(5.4)$ & $93(5.7)$ & $62(4.3)$ & $49(4.2)$ & $37(3.7)$ & \\
\hline \multicolumn{7}{|l|}{ Occupation } \\
\hline Managers and profession & $70(9.7)$ & $161(9.8)$ & $147(10.1)$ & $173(14.7)$ & $138(14.0)$ & $<0.001$ \\
\hline Office worker, sales, service & $130(17.9)$ & $267(16.2)$ & $333(22.9)$ & 319 (27.1) & $296(29.9)$ & \\
\hline Laborers, agriculture & $22(3.0)$ & $71(4.3)$ & $56(3.8)$ & $46(3.9)$ & $51(5.2)$ & \\
\hline Not in labor force & $491(67.7)$ & $1112(67.6)$ & $899(61.7)$ & $621(52.7)$ & $483(48.8)$ & \\
\hline Missing $^{3}$ & $12(1.7)$ & $35(2.1)$ & $22(1.5)$ & $19(1.6)$ & $21(2.1)$ & \\
\hline \multicolumn{7}{|l|}{ Alcohol consumption } \\
\hline Non-drinker & $540(74.5)$ & $1002(60.9)$ & $793(54.4)$ & $565(48.0)$ & $416(42.1)$ & $<0.001$ \\
\hline Ex-drinker & $39(5.4)$ & $97(5.9)$ & $73(5.0)$ & $58(4.9)$ & $61(6.2)$ & \\
\hline Current drinker & $144(19.9)$ & $544(33.1)$ & $586(40.2)$ & $553(46.9)$ & $512(51.8)$ & \\
\hline Missing $^{3}$ & $2(0.3)$ & $3(0.2)$ & $5(0.3)$ & $2(0.2)$ & $0(0.0)$ & \\
\hline \multicolumn{7}{|l|}{ Smoking status } \\
\hline Non-smoker & $691(95.3)$ & $1551(94.2)$ & $1375(94.4)$ & $1092(92.7)$ & $873(88.3)$ & $<0.001$ \\
\hline Ex-smoker & $14(1.9)$ & $53(3.2)$ & $45(3.1)$ & $49(4.2)$ & $56(5.7)$ & \\
\hline Current smoker & $13(1.8)$ & $34(2.1)$ & $30(2.1)$ & $30(2.6)$ & $58(5.9)$ & \\
\hline Missing $^{3}$ & $7(1.0)$ & $8(0.5)$ & $7(0.5)$ & $7(0.6)$ & $2(0.2)$ & \\
\hline Regular exercise (yes) & $398(54.9)$ & $925(56.2)$ & $774(53.1)$ & $564(47.9)$ & $447(45.2)$ & $<0.001$ \\
\hline Age at menarche (years) & $14.9 \pm 1.7$ & $14.8 \pm 1.7$ & $14.7 \pm 2.0$ & $14.4 \pm 1.7$ & $14.5 \pm 1.6$ & $<0.001$ \\
\hline Menopause (yes) & $523(71.1)$ & $1094(66.5)$ & $890(61.1)$ & $598(50.8)$ & $486(49.1)$ & $<0.001$ \\
\hline Age at menopause ${ }^{4}$ (years) & $49.3 \pm 4.8$ & $49.2 \pm 5.0$ & $49.4 \pm 4.8$ & $49.4 \pm 4.7$ & $49.1 \pm 4.8$ & 0.845 \\
\hline \multicolumn{7}{|l|}{ Postmenopausal hormone use ${ }^{4}$} \\
\hline Never & $341(65.2)$ & $713(65.2)$ & 597 (67.1) & $421(70.4)$ & $353(72.6)$ & 0.001 \\
\hline Ever & $164(31.4)$ & $345(31.5)$ & $268(30.1)$ & $156(26.1)$ & $121(24.9)$ & \\
\hline Total caloric intake (kcal/day) & $1562.7 \pm 603.1$ & $1576.2 \pm 586.2$ & $1629.2 \pm 554.4$ & $1666.3 \pm 573.0$ & $1763.8 \pm 661.6$ & $<0.001$ \\
\hline Coffee intake (cups/day) & $0.0 \pm 0.0$ & $0.4 \pm 0.3$ & $1.0 \pm 0.1$ & $2.0 \pm 0.0$ & $3.8 \pm 1.1$ & $<0.001$ \\
\hline Coffee sugar addition (g/day) & $0.0 \pm 0.0$ & $0.9 \pm 1.5$ & $2.1 \pm 2.2$ & $4.2 \pm 3.9$ & $5.8 \pm 6.2$ & $<0.001$ \\
\hline Coffee creamer addition (g/day) & $0.0 \pm 0.0$ & $0.5 \pm 0.9$ & $1.4 \pm 1.8$ & $3.1 \pm 3.2$ & $4.4 \pm 5.0$ & $<0.001$ \\
\hline
\end{tabular}

1 Data presented as unadjusted mean \pm SD for continuous variables or prevalence (\%) for categorical variables; ${ }^{2} p$ for trend was calculated using the Mantel-Haenszel $\chi^{2}$ test for categorical variables and generalized linear models for continuous variables; ${ }^{3}$ Missing included no response or unwilling to respond; ${ }^{4}$ In postmenopausal women. 
Table 2. Anthropometric measurements of the study participants stratified by coffee consumption category.

\begin{tabular}{|c|c|c|c|c|c|c|}
\hline \multirow[b]{2}{*}{ Anthropometric Factor } & \multicolumn{5}{|c|}{ Daily Coffee Consumption } & \multirow[b]{2}{*}{$p$ for Trend } \\
\hline & None $(n=725)$ & $<1$ Cup/Day $(n=1646)$ & 1-2 Cups/Day $(n=1457)$ & 2-3 Cups/Day $(n=1178)$ & $\geq 3$ Cups/Day $(n=989)$ & \\
\hline \multicolumn{7}{|l|}{ Height $(\mathrm{cm})$} \\
\hline Model 1 & $156.70 \pm 5.43$ & $157.31 \pm 5.25$ & $157.42 \pm 5.19$ & $157.83 \pm 5.03$ & $158.01 \pm 4.98$ & $<0.001$ \\
\hline Model 2 & $157.31 \pm 5.09$ & $157.65 \pm 4.89$ & $157.42 \pm 4.89$ & $157.51 \pm 4.82$ & $157.59 \pm 4.64$ & 0.583 \\
\hline Model 3 & $157.15 \pm 5.09$ & $157.54 \pm 4.89$ & $157.40 \pm 4.89$ & $157.62 \pm 4.82$ & $157.79 \pm 4.61$ & 0.186 \\
\hline \multicolumn{7}{|l|}{ Weight (kg) } \\
\hline Model 1 & $55.18 \pm 7.22$ & $57.47 \pm 7.64$ & $57.61 \pm 7.61$ & $58.32 \pm 7.72$ & $58.62 \pm 7.69$ & $<0.001$ \\
\hline Model 2 & $55.12 \pm 7.24$ & $57.57 \pm 7.73$ & $57.51 \pm 7.50$ & $58.36 \pm 7.59$ & $58.53 \pm 7.58$ & $<0.001$ \\
\hline Model 3 & $54.80 \pm 7.24$ & $57.35 \pm 7.73$ & $57.45 \pm 7.48$ & $58.57 \pm 7.59$ & $58.93 \pm 7.54$ & $<0.001$ \\
\hline \multicolumn{7}{|l|}{ Body mass index $\left(\mathrm{kg} / \mathrm{m}^{2}\right)$} \\
\hline Model 1 & $22.49 \pm 2.88$ & $23.23 \pm 2.94$ & $23.27 \pm 3.08$ & $23.42 \pm 3.00$ & $23.49 \pm 2.99$ & $<0.001$ \\
\hline Model 2 & $22.29 \pm 2.82$ & $23.17 \pm 2.94$ & $23.23 \pm 2.96$ & $23.53 \pm 2.84$ & $23.57 \pm 2.85$ & $<0.001$ \\
\hline Model 3 & $22.20 \pm 2.82$ & $23.12 \pm 2.94$ & $23.21 \pm 2.96$ & $23.58 \pm 2.84$ & $23.68 \pm 2.84$ & $<0.001$ \\
\hline \multicolumn{7}{|l|}{ Waist circumference $(\mathrm{cm})$} \\
\hline Model 1 & $72.97 \pm 7.42$ & $74.36 \pm 7.33$ & $74.35 \pm 7.44$ & $74.29 \pm 7.53$ & $74.36 \pm 7.65$ & $<0.001$ \\
\hline Model 2 & $72.25 \pm 6.87$ & $74.09 \pm 7.11$ & $74.23 \pm 6.87$ & $74.66 \pm 7.03$ & $74.71 \pm 2.28$ & $<0.001$ \\
\hline Model 3 & $72.11 \pm 6.87$ & $73.99 \pm 7.11$ & $74.20 \pm 6.86$ & $74.76 \pm 7.04$ & $74.91 \pm 7.26$ & $<0.001$ \\
\hline
\end{tabular}

Data presented as adjusted mean \pm SD. Model 1 was unadjusted. Model 2 was adjusted for age, education level, occupation, alcohol intake, smoking status, regular exercise, total energy intake. Model 3 was adjusted for covariates in Model $2+$ sugar and creamer additive use. 
Table 3. Odds ratio (OR) and $95 \%$ confidence interval (CI) for the prevalence of obesity as defined by body mass index ( $\geq 25)$ according to coffee consumption category.

\begin{tabular}{|c|c|c|c|c|c|}
\hline \multirow{2}{*}{$\begin{array}{l}\text { Daily Coffee } \\
\text { Consumption }\end{array}$} & \multicolumn{2}{|c|}{ No of Subjects } & \multirow{2}{*}{ Model 1} & \multirow{2}{*}{ Model 2} & \multirow{2}{*}{ Model 3} \\
\hline & Without Obesity ${ }^{1}$ & With Obesity & & & \\
\hline \multicolumn{6}{|l|}{ All subjects } \\
\hline None & $612(13.4)$ & $113(7.9)$ & 1.00 (ref) & 1.00 (ref) & 1.00 (ref) \\
\hline$<1$ cup/day & $1269(27.8)$ & $377(26.4)$ & $1.61(1.28-2.03)$ & $1.76(1.39-2.23)$ & $1.75(1.38-2.22)$ \\
\hline $1-2$ cups/day & $1096(24.0)$ & $361(25.3)$ & $1.78(1.41-2.25)$ & $2.05(1.61-2.60)$ & $2.04(1.60-2.60)$ \\
\hline $2-3$ cups/day & $874(19.1)$ & $304(21.3)$ & $1.88(1.48-2.39)$ & $2.36(1.84-3.03)$ & $2.35(1.81-3.05)$ \\
\hline$\geq 3$ cups/day & $717(15.7)$ & $272(19.1)$ & $2.06(1.61-2.62)$ & $2.54(1.96-3.28)$ & $2.52(1.91-3.34)$ \\
\hline$p$ for trend ${ }^{2}$ & & & $<0.001$ & $<0.001$ & $<0.001$ \\
\hline \multicolumn{6}{|c|}{ Premenopausal women } \\
\hline None & $177(9.2)$ & $25(5.3)$ & 1.00 (ref) & 1.00 (ref) & 1.00 (ref) \\
\hline$<1 \mathrm{cup} /$ day & $452(23.4)$ & $100(21.1)$ & $1.57(0.98-2.51)$ & $1.61(0.99-2.60)$ & $1.63(1.00-2.64)$ \\
\hline $1-2$ cups/day & $458(23.7)$ & $109(23.0)$ & $1.69(1.06-2.69)$ & $1.70(1.05-2.75)$ & $1.75(1.08-2.85)$ \\
\hline $2-3$ cups/day & $458(23.7)$ & $122(25.7)$ & $1.89(1.19-3.00)$ & $1.89(1.17-3.06)$ & $2.00(1.22-3.27)$ \\
\hline$\geq 3$ cups/day & $385(20.0)$ & $118(24.9)$ & $2.17(1.36-3.46)$ & $2.10(1.29-3.41)$ & $2.28(1.36-3.82)$ \\
\hline$p$ for trend ${ }^{2}$ & & & 0.001 & 0.007 & 0.006 \\
\hline \multicolumn{6}{|c|}{ Postmenopausal women } \\
\hline None & $435(16.5)$ & $88(9.2)$ & 1.00 (ref) & 1.00 (ref) & 1.00 (ref) \\
\hline$<1$ cup/day & 817 (31.0) & $277(29.1)$ & $1.68(1.28-2.19)$ & $1.79(1.36-2.35)$ & $1.76(1.34-2.32)$ \\
\hline $1-2$ cups/day & $638(24.2)$ & $252(26.4)$ & $1.95(1.49-2.56)$ & $2.16(1.63-2.86)$ & $2.10(1.58-2.79)$ \\
\hline 2-3 cups/day & $416(15.8)$ & $182(19.1)$ & $2.16(1.62-2.88)$ & $2.52(1.87-3.39)$ & $2.40(1.75-3.30)$ \\
\hline$\geq 3$ cups/day & 332 (12.6) & $154(16.2)$ & $2.29(1.70-3.09)$ & $2.66(1.95-3.64)$ & $2.52(1.79-3.54)$ \\
\hline $\bar{p}$ for trend ${ }^{2}$ & & & $<0.001$ & $<0.001$ & $<0.001$ \\
\hline
\end{tabular}


Table 4. Odds ratio (OR) and 95\% confidence interval (CI) for the prevalence of abdominal obesity as defined by waist circumference according to coffee consumption category.

\begin{tabular}{|c|c|c|c|c|c|}
\hline \multirow{2}{*}{$\begin{array}{l}\text { Daily Coffee } \\
\text { Consumption }\end{array}$} & \multicolumn{2}{|c|}{ No of Subjects } & \multirow{2}{*}{ Model 1} & \multirow{2}{*}{ Model 2} & \multirow{2}{*}{ Model 3} \\
\hline & Without Obesity $^{1}$ & With Obesity & & & \\
\hline \multicolumn{6}{|l|}{ All subjects } \\
\hline None & $597(12.8)$ & $128(9.6)$ & 1.00 (ref) & 1.00 (ref) & 1.00 (ref) \\
\hline$<1$ cup/day & $1275(27.3)$ & $371(27.9)$ & $1.36(1.09-1.70)$ & $1.52(1.21-1.92)$ & $1.52(1.21-1.92)$ \\
\hline $1-2$ cups/day & $1122(24.1)$ & $335(25.2)$ & $1.39(1.11-1.75)$ & $1.70(1.34-2.15)$ & $1.71(1.34-2.17)$ \\
\hline $2-3$ cups/day & $916(19.6)$ & $262(19.7)$ & $1.33(1.05-1.69)$ & $1.88(1.47-2.41)$ & $1.93(1.48-2.51)$ \\
\hline$\geq 3$ cups/day & $755(16.2)$ & $234(17.6)$ & $1.45(1.14-1.84)$ & $2.03(1.57-2.63)$ & $2.11(1.59-2.79)$ \\
\hline$p$ for trend ${ }^{2}$ & & & 0.083 & $<0.001$ & $<0.001$ \\
\hline \multicolumn{6}{|c|}{ Premenopausal women } \\
\hline None & $185(9.1)$ & $17(4.5)$ & 1.00 (ref) & 1.00 (ref) & 1.00 (ref) \\
\hline$<1$ cup/day & $466(23.0)$ & $86(22.9)$ & $2.01(1.16-3.47)$ & $2.16(1.23-3.78)$ & $2.18(1.25-3.83)$ \\
\hline $1-2$ cups / day & $485(23.9)$ & $82(21.9)$ & $1.84(1.06-3.19)$ & $1.96(1.11-3.44)$ & $2.00(1.14-3.54)$ \\
\hline $2-3$ cups/day & $484(23.9)$ & $96(25.6)$ & $2.16(1.25-3.71)$ & $2.36(1.35-4.14)$ & $2.51(1.41-4.46)$ \\
\hline$\geq 3$ cups/day & $409(20.2)$ & $94(25.1)$ & $2.50(1.45-4.31)$ & $2.59(1.47-4.55)$ & $2.82(1.55-5.12)$ \\
\hline$p$ for trend ${ }^{2}$ & & & 0.007 & 0.012 & 0.010 \\
\hline \multicolumn{6}{|c|}{ Postmenopausal women } \\
\hline None & $412(15.6)$ & $111(11.6)$ & 1.00 (ref) & 1.00 (ref) & 1.00 (ref) \\
\hline$<1$ cup/day & 809 (30.7) & $285(29.8)$ & $1.31(1.02-1.68)$ & $1.40(1.08-1.82)$ & $1.40(1.08-1.81)$ \\
\hline $1-2$ cups/day & $637(24.2)$ & $253(26.5)$ & $1.47(1.14-1.90)$ & $1.66(1.27-2.17)$ & $1.67(1.27-2.19)$ \\
\hline $2-3$ cups/day & $432(16.4)$ & $166(17.4)$ & $1.43(1.08-1.88)$ & $1.76(1.32-2.35)$ & $1.79(1.31-2.44)$ \\
\hline$\geq 3$ cups/day & $346(13.1)$ & $140(14.7)$ & $1.50(1.13-2.00)$ & $1.87(1.37-2.54)$ & $1.90(1.36-2.67)$ \\
\hline$p$ for trend ${ }^{2}$ & & & 0.023 & $<0.001$ & 0.001 \\
\hline
\end{tabular}

Model 1 was unadjusted. Model 2 was adjusted for age, education level, occupation, alcohol intake, smoking status, regular exercise, total energy intake. Model 3 was adjusted for covariates in Model $2+$ sugar and creamer additive use. ${ }^{1}$ Obesity was defined as a waist circumference of $\geq 80 \mathrm{~cm} ;{ }^{2} p$ for trend was calculated using the median value of each category as a continuous variable. 


\section{Discussion}

This study investigated the relationship between coffee consumption and obesity using BMI and WC in Korean women aged 30-70 years. Women who consumed coffee more than 3 times per day exhibited significantly greater BMI and WC values than did women who were not coffee drinkers after adjusting for age, education level, occupation, alcohol intake, smoking status, regular exercise, total energy intake, and the use of sugar and creamer additives. After stratifying participants by menopausal status, a positive association between coffee consumption and obesity remained for both premenopausal and postmenopausal women.

In several previous studies, coffee consumption was not related to obesity indices, such as BMI or WC [24-27]. In a cross-sectional study of 3823 National Health and Nutrition Examination Survey participants in the United States, coffee consumption was not associated with BMI or WC in either men or women. However, the BMI was higher among people who used artificial sweeteners in their coffee [25]. In a longitudinal study of Dutch people, coffee intake was not related to BMI and WC [26].

However, a cross-sectional study of 8821 people in Poland reported that the prevalence of obesity was lower in participants who drank more than three cups of coffee a day than in participants who drank less than one cup of coffee a day [18]. A cross-sectional study of 1902 Japanese men and women over age 40 also showed an inverse relationship between coffee consumption and WC [17].

Furthermore, in a prospective study of 14,629 Finnish men and women, BMI for both men and women increased with increasing coffee intake [22]. According to the results from a prospective study of Swedish women, the group who consumed more than 6 cups of coffee daily tended to have a higher BMI than the group who consumed less than 2 cups daily [23]. In a cross-sectional study of Koreans, women who consumed coffee more than three times a day had higher BMI and WC values than did women who consumed coffee less than once a day [31].

In one study, the type of coffee consumed was found to be associated with the odds of obesity. Instant coffee drinkers who used sugar and creamer had significantly higher risks of overweight (BMI > 23) and abdominal obesity than did non-drinkers. However, filtered coffee drinkers did not show a significant increase in overweight or abdominal obesity compared with non-drinkers [32]. In the present study, high coffee consumption with the additional intake of sugar and creamer was associated with higher obesity prevalence, as assessed by the Asian standards of BMI and WC. Therefore, differences in results among studies from various regions of the world regarding the relationship between coffee consumption and obesity might partially be due to differences in the type of coffee consumed and the use of coffee additives.

Caffeine is one of the chemicals in coffee that can affect obesity. Caffeine has been reported to induce hyperactivity of the sympathetic nervous system, thereby accelerating the consumption of energy and loss of body fat [33,34]. After 16 weeks of caffeine intake, caffeine stimulated the breakdown of fat cells and stimulated the secretion of catecholamines to increase the oxidation and metabolism of fatty acids, thereby inhibiting weight gain and body fat accumulation in animals [35]. In human studies, caffeine intake has also been found to increase heat production and energy consumption $[34,36]$. However, in the present study, the BMIs and WCs of Korean women increased as coffee consumption increased. This finding might be related to the fact that the most common type of coffee consumed in Korea is instant coffee mix that includes sugar and creamer [10,37]. The average amount of sugar in one serving ( $12 \mathrm{~g}$ ) of instant coffee mix is $5.7 \mathrm{~g}$, and the saturated fat content due to the non-dairy creamer is $1.2 \mathrm{~g}$, accounting for $50 \%$ and $10 \%$ of the coffee mix by weight, respectively $[38,39]$. Therefore, the additional calories contained in the coffee mix might have contributed to the body weight gain of the subjects.

In this study, the risk of obesity remained after adjusting for the use of sugar and non-dairy creamer. Instant coffee and ground bean coffee manufacturing methods differ; therefore, differences in ingredient composition and content after coffee extraction may exist. However, we did not directly record the type of coffee consumed by the subjects. In previous studies, filtered coffee had different 
physiological effects than boiled coffee by filtering of lipophilic substances [28,40]. Further studies are warranted to identify residual confounding factors.

Women show changes in fat metabolism after menopause. Premenopausal estrogen accumulates fat in the hips and thighs, but after menopause, the estrogen deficiency redistributes body fat and promotes abdominal obesity [41]. Because coffee contains some phytoestrogen components [14], we examined the possibility that menopause modifies the effects of coffee. However, the effect of coffee consumption on abdominal obesity was not altered by menopause.

The strengths of this study are as follows. First, we performed a large-scale study to assess the relationship between coffee consumption and obesity risk in Korean women. Second, we collected data on the amount of coffee consumed and the amounts of sugar and non-dairy creamer that were added to coffee using a food frequency questionnaire. The limitations of this study are as follows. First, because this study has a cross-sectional design, the determination of a causal relationship between coffee consumption and obesity is difficult. Second, a detailed investigation of the type of coffee consumed, i.e., instant vs. brewed, was not performed at the time the FFQ was administered. Finally, because this study was conducted in participants who received a health screen, the possibility of selection bias cannot be excluded. Recently, a rapidly increasing trend toward a preference for high-quality, roasted bean brewed coffee over instant coffee mix has been noted, particularly among young people in Korea [32,37]. Given changes in coffee consumption patterns, future studies should examine potential changes in obesity prevalence rates.

\section{Conclusions}

In this cross-sectional study, frequent coffee consumption by Korean women was associated with high obesity prevalence. However, this sample of participants demonstrated additional intake of sugar and creamer with their coffee consumption, which might contribute to the increased prevalence of obesity. The positive association between coffee consumption and obesity was not altered by menopause. The importance of coffee consumption in the risk of obesity should be pursued in further studies, such as well-designed, large-scale, prospective cohort studies, in order to elucidate the causal relationship between coffee consumption and the etiology of obesity.

Acknowledgments: This work was supported by the National Cancer Center, Korea, No. 1510040.

Author Contributions: J.L. and H.Y.K. contributed equally to this work; J.L. and J.K. designed, analyzed and interpreted the data; H.Y.K. and J.K. wrote the manuscript. All authors read and approved the final manuscript.

Conflicts of Interest: The authors declare no conflict of interest.

\section{References}

1. World Health Organization. Controlling the Global Obesity Epidemic. Available online: http://www.who. int/nutrition/topics/obesity/en/ (accessed on 10 August 2017).

2. World Health Organization. Global Health Observatory Data. 2017. Available online: http://www.who.int/ gho/ncd/risk_factors/overweight/en/ (accessed on 10 August 2017).

3. Nguyen, D.M.; El-Serag, H.B. The epidemiology of obesity. Gastroenterol. Clin. N. Am. 2010, 39, 1-7. [CrossRef] [PubMed]

4. Jee, S.H.; Pastor-Barriuso, R.; Appel, L.J.; Suh, I.; Miller, E.R., 3rd; Guallar, E. Body mass index and incident ischemic heart disease in south Korean men and women. Am. J. Epidemiol. 2005, 162, 42-48. [PubMed]

5. Haslam, D.W.; James, W.P. Obesity. Lancet 2005, 366, 1197-1209. [CrossRef]

6. Hruby, A.; Manson, J.E.; Qi, L.; Malik, V.S.; Rimm, E.B.; Sun, Q.; Willett, W.C.; Hu, F.B. Determinants and consequences of obesity. Am. J. Public Health 2016, 106, 1656-1662. [CrossRef] [PubMed]

7. Vartanian, L.R.; Schwartz, M.B.; Brownell, K.D. Effects of soft drink consumption on nutrition and health: A systematic review and meta-analysis. Am. J. Public Health 2007, 97, 667-675. [CrossRef] [PubMed]

8. Schulze, M.B.; Manson, J.E.; Ludwig, D.S.; Colditz, G.A.; Stampfer, M.J.; Willett, W.C.; Hu, F.B. Sugar-sweetened beverages, weight gain, and incidence of type 2 diabetes in young and middle-aged women. JAMA 2004, 292, 927-934. [CrossRef] [PubMed] 
9. Kang, S.; Na, Y. The analysis toward consumption state, import and export in the world coffee market-the case of Korea, USA, Japan market. Korean. J. Clin. Res. 2004, 10, 65-82.

10. USDA Agricultural Service. Coffee Market Brief Update-Seoul ATO; Global Agricultural Information Network Report; United States Department of Agriculture Foreign Agricultural Service: Washington, DC, USA, 2015.

11. Ministry of Health and Welfare, Korea Centers for Disease Control and Prevention. Korea Health Statistics 2015: Korea National Health and Nutrition Examination Survey (KNHANES VI-3); Korea Centers for Disease Control and Prevention: Cheongju, Korea, 2016.

12. Ranheim, T.; Halvorsen, B. Coffee consumption and human health-beneficial or detrimental?-Mechanisms for effects of coffee consumption on different risk factors for cardiovascular disease and type 2 diabetes mellitus. Mol. Nutr. Food Res. 2005, 49, 274-284. [PubMed]

13. Butt, M.S.; Sultan, M.T. Coffee and its consumption: Benefits and risks. Crit. Rev. Food Sci. Nutr. 2011, 51, 363-373. [CrossRef] [PubMed]

14. Santos, R.M.M.; Lima, D.R.A. Coffee consumption, obesity and type 2 diabetes: A mini-review. Eur. J. Nutr. 2016, 55, 1345-1358. [CrossRef] [PubMed]

15. Bidel, S.; Tuomilehto, J. The emerging health benefits of coffee with an emphasis on type 2 diabetes and cardiovascular disease. Eur. Endocrinol. 2012, 9, 99-106. [CrossRef]

16. Meng, S.; Cao, J.; Feng, Q.; Peng, J.; Hu, Y. Roles of chlorogenic acid on regulating glucose and lipids metabolism: A review. Evid. Based Complement. Alternat. Med. 2013, 2013, 801457. [CrossRef] [PubMed]

17. Hino, A.; Adachi, H.; Enomoto, M.; Furuki, K.; Shigetoh, Y.; Ohtsuka, M.; Kumagae, S.; Hirai, Y.; Jalaldin, A.; Satoh, A.; et al. Habitual coffee but not green tea consumption is inversely associated with metabolic syndrome: An epidemiological study in a general Japanese population. Diabetes Res. Clin. Pract. 2007, 76, 383-389. [CrossRef] [PubMed]

18. Grosso, G.; Stepaniak, U.; Micek, A.; Topor-Madry, R.; Pikhart, H.; Szafraniec, K.; Pajak, A. Association of daily coffee and tea consumption and metabolic syndrome: Results from the polish arm of the HAPIEE study. Eur. J. Nutr. 2015, 54, 1129-1137. [CrossRef] [PubMed]

19. Greenberg, J.; Axen, K.; Schnoll, R.; Boozer, C. Coffee, tea and diabetes: The role of weight loss and caffeine. Int. J. Obes. 2005, 29, 1121-1129. [CrossRef] [PubMed]

20. Lopez-Garcia, E.; van Dam, R.M.; Rajpathak, S.; Willett, W.C.; Manson, J.E.; Hu, F.B. Changes in caffeine intake and long-term weight change in men and women. Am. J. Clin. Nutr. 2006, 83, 674-680. [PubMed]

21. Greenberg, J.A.; Boozer, C.N.; Geliebter, A. Coffee, diabetes, and weight control. Am. J. Clin. Nutr. 2006, 84, 682-693. [PubMed]

22. Tuomilehto, J.; Hu, G.; Bidel, S.; Lindström, J.; Jousilahti, P. Coffee consumption and risk of type 2 diabetes mellitus among middle-aged Finnish men and women. J. Am. Med. Assoc. 2004, 291, 1213-1219. [CrossRef] [PubMed]

23. Rosengren, A.; Dotevall, A.; Wilhelmsen, L.; Thelle, D.; Johansson, S. Coffee and incidence of diabetes in Swedish women: A prospective 18-year follow-up study. J. Intern. Med. 2004, 255, 89-95. [CrossRef] [PubMed]

24. Matsuura, H.; Mure, K.; Nishio, N.; Kitano, N.; Nagai, N.; Takeshita, T. Relationship between coffee consumption and prevalence of metabolic syndrome among Japanese civil servants. J. Epidemiol. 2012, 22, 160-166. [CrossRef] [PubMed]

25. Bouchard, D.R.; Ross, R.; Janssen, I. Coffee, tea and their additives: Association with BMI and waist circumference. Obes. Facts 2010, 3, 345-352. [CrossRef] [PubMed]

26. Balk, L.; Hoekstra, T.; Twisk, J. Relationship between long-term coffee consumption and components of the metabolic syndrome: The Amsterdam growth and health longitudinal study. Eur. J. Epidemiol. 2009, 24, 203-209. [CrossRef] [PubMed]

27. Grosso, G.; Marventano, S.; Galvano, F.; Pajak, A.; Mistretta, A. Factors associated with metabolic syndrome in a mediterranean population: Role of caffeinated beverages. J. Epidemiol. 2014, 24, 327-333. [CrossRef] [PubMed]

28. Dam, R.M. Coffee consumption and risk of type 2 diabetes, cardiovascular diseases, and cancer. Appl. Physiol. Nutr. Metab. 2008, 33, 1269-1283. [PubMed]

29. Ahn, Y.; Kwon, E.; Shim, J.E.; Park, M.K.; Joo, Y.; Kim, K.; Park, C.; Kim, D.H. Validation and reproducibility of food frequency questionnaire for Korean genome epidemiologic study. Eur. J. Clin. Nutr. 2007, 61, 1435-1441. [CrossRef] [PubMed] 
30. World Health Organization. The Asia-Pacific Perspective: Redefining Obesity and Its Treatment; International Obesity Task Force: Brussels, Belgium, 2000.

31. Kim, J.H.; Park, Y.S. Light coffee consumption is protective against sarcopenia, but frequent coffee consumption is associated with obesity in Korean adults. Nutr. Res. 2017, 41, 97-102. [CrossRef] [PubMed]

32. Kim, H.J.; Cho, S.; Jacobs, D.R., Jr.; Park, K. Instant coffee consumption may be associated with higher risk of metabolic syndrome in Korean adults. Diabetes Res. Clin. Pract. 2014, 106, 145-153. [CrossRef] [PubMed]

33. Westerterp-Plantenga, M.; Diepvens, K.; Joosen, A.M.; Berube-Parent, S.; Tremblay, A. Metabolic effects of spices, teas, and caffeine. Physiol. Behav. 2006, 89, 85-91. [CrossRef] [PubMed]

34. Acheson, K.J.; Gremaud, G.; Meirim, I.; Montigon, F.; Krebs, Y.; Fay, L.B.; Gay, L.J.; Schneiter, P.; Schindler, C.; Tappy, L. Metabolic effects of caffeine in humans: Lipid oxidation or futile cycling? Am. J. Clin. Nutr. 2004, 79, 40-46. [PubMed]

35. Zheng, G.; Sayama, K.; Okubo, T.; Juneja, L.R.; Oguni, I. Anti-obesity effects of three major components of green tea, catechins, caffeine and theanine, in mice. In Vivo 2004, 18, 55-62. [PubMed]

36. Arciero, P.J.; Bougopoulos, C.L.; Nindl, B.C.; Benowitz, N.L. Influence of age on the thermic response to caffeine in women. Metabolism 2000, 49, 101-107. [CrossRef]

37. Je, Y.; Jeong, S.; Park, T. Coffee consumption patterns in Korean adults: The Korean National Health and Nutrition Examination Survey (2001-2011). Asia Pac. J. Clin. Nutr. 2014, 23, 691-702. [PubMed]

38. Lee, B.; Lee, H.J.; Cho, E.; Hwang, K.T. Fatty acid composition of fats in commercial coffee creamers and instant coffee mixes and their sensory characteristics. J. Korean Soc. Food Sci. Nutr. 2012, 41, 362-368. [CrossRef]

39. Kim, K.Y.; Yang, S.J.; Yon, J.M. Consumption of instant coffee mix and risk of metabolic syndrome in subjects that visited a health examination center in Gwangju. J. Korean Soc. Food Sci. Nutr. 2017, 46, 630-638. [CrossRef]

40. Cai, L.; Ma, D.; Zhang, Y.; Liu, Z.; Wang, P. The effect of coffee consumption on serum lipids: A meta-analysis of randomized controlled trials. Eur. J. Clin. Nutr. 2012, 66, 872-877. [CrossRef] [PubMed]

41. Carr, M.C. The emergence of the metabolic syndrome with menopause. J. Clin. Endocrinol. Metab. 2003, 88, 2404-2411. [CrossRef] [PubMed] 